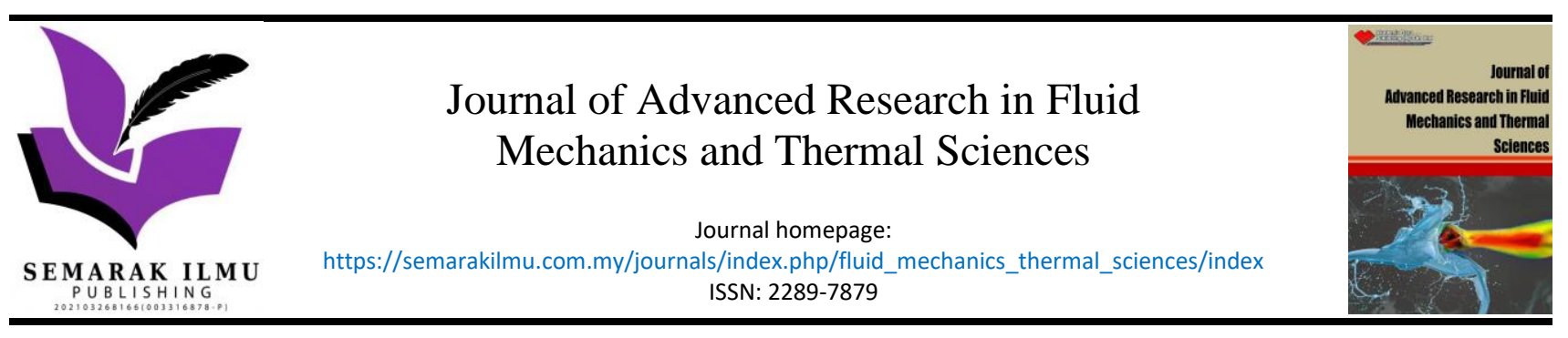

\title{
CFD Analysis of Flow Over Pickup Truck with And Without Covering Cargo Area Using OpenFOAM
}

\author{
Abed Alrzaq Alshqirate ${ }^{1}$, Dastan Zrar Ghafoor ${ }^{2}$, Sachin L. Borse ${ }^{3, *}$ \\ Mechanical Engineering Department, Faculty of Engineering Technology, Al-Balqa Applied University, Jordan \\ Department of Technical Mechanical and Energy Engineering, Erbil Technical Engineering College, Erbil Polytechnic University, Kirkuk Road, \\ Erbil, 44001, Kurdistan Region, Iraq \\ 3 Imperial College of Engineering and Research, Pune University, Pune, India
}

\section{$\begin{array}{ll}\text { ARTICLE INFO ABSTRACT } & \text { ABTS }\end{array}$}

\section{Article history:}

Received 27 October 2021

Received in revised form 29 November 2021

Accepted 30 November 2021

Available online 7 December 2021

\section{Keywords:}

Computational Fluid Dynamics; pickup truck; OpenFOAM

\begin{abstract}
Pickup truck serves purpose as car as well as small truck. Pickup truck is popularly used in USA and Saudi Arabia. Pickup truck consists of enclosed cab and an open cargo space. Here CFD analysis of full scale pickup truck is performed using free CFD software OpenFOAM for speed range from $40 \mathrm{~km} / \mathrm{hr}$ to $140 \mathrm{~km} / \mathrm{hr}$. For turbulence modelling k$\omega$ model is used. This work investigates effect of covering cargo area on aerodynamics drag. Covering cargo area decreases drag coefficient by $5.2 \%$ by horizontally covering cargo area whereas decreases by $13 \%$ by inclined surface covering cargo area. Thus, covering cargo area reduces drag coefficient as recirculation zone is reduced. Inclined cover case shows drastic rise in lift force, requiring attention for safety as traction will be affected.
\end{abstract}

\section{Introduction}

Pickup truck serves purpose as car as well as small truck. Pickup truck is popularly used in USA and Saudi Arabia. To carry any raw material or to carry final product of low weight ranging from $1000 \mathrm{~kg}$ to $1200 \mathrm{~kg}$ pickup truck is used. Due to low weight carrying capacity, pickup truck is also used in Agricultural sector extensively. Pickup truck consists of enclosed cab followed by cargo space. Few studies exist about aerodynamics investigation of pickup truck. CFD investigation for scaled model of pickup truck was conducted using k-epsilon turbulence model. Scaling used was 1:12 similar to experimental data of Khalighi [1]. CFD results showed better agreement with experimental result of Khalighi [1]. The commercial software CFD Expert was used for CFD analysis. Detailed flow field was studied for a better understanding of pickup truck [2].

The drag characteristics of scaled down model of the pickup truck were experimentally studied for different bed geometry with the variation of the bed length and the bed height. PIV (Particle Image Velocity) technique was used to visualise flow around the tailgate and flow field on the upper side of the tailgate and sidewalls were visualized with the oil-paint method of visualisation. Result

\footnotetext{
* Corresponding author.

E-mail address: sachinlb@yahoo.co.uk
}

https://doi.org/10.37934/arfmts.90.1.4051 
showed that drag coefficients showed trend of first increase and then decrease for bed height. The bed height was found the principle factor for the bed small length, whereas the reverse flow in wake region was major factor for the bed with more length. Size and location of the reverse flow in wake was dependent on the bed geometry [3].

CFD study of full scale pickup truck was conducted using CFD software STAR CCM + and turbulence was handled with SST k- $\omega$ model. Here effect of bed length increase was studied for three speeds $48.3 \mathrm{kmph}, 80.5 \mathrm{kmph}$ and $112.6 \mathrm{kmph}$. This investigation aimed at assessing effect of spoiler on rear gate and taper on backside of top of cabin of pickup truck. It was observed that the taper in roof at top of cabin towards backside causes appreciable reduction in drag coefficient of the pickup truck. The spoiler on rear gate showed lower drag coefficient at low speeds and slightly higher at high pickup truck speed [4].

Pickup truck was studied with CFD to evaluate performance of various aerodynamic add-on devices attached to the pickup truck to reduce drag coefficient of pickup truck. The thesis is focused on study of presence of devices like tonneau cover, tail plates, rear roof garnish, tail plates, airdam, 3D aerocap and traditional canopy on aerodynamics performance of pickup truck. Aerocap with rear inclination angle of $12^{\circ}$ gave maximum drag reduction. Maximum reduction in drag coefficient observed was about $19.84 \%$ [5].

Six car models of pickup truck Normal, Wildtrak, Covered pickup box, SUV, Front grill and Sedan having same frontal area were studied using commercial CFD code FLUENT and wind tunnel testing. The ratio of the model to the actual size of pick-up truck was 1:20. Models were tested for speed range $36-90 \mathrm{~km} / \mathrm{hr}$ in the wind tunnel and CFD. Investigation of the aerodynamic characteristics was aimed to reduce the coefficient of drag due to the wake at the rear body of the pickup car. The result showed reduction in drag coefficient from normal case by $5 \%$ to $33.3 \%$, except SUV case showed increase in drag coefficient by $10 \%$. The study confirmed that reduction in wake at rear of pickup can significantly affect the drag coefficient [6].

Steady flow field over a pickup truck was simulated using commercial CFD software Fluent. CFD results were compared with the existing experiments for a generic pickup truck. Result showed similarity the flow structures obtained using the CFD calculations and measured mean flows. Pressure on surface of body of the truck was predicted nearly close by the Computational Fluid Dynamics software. Coefficients of drags were compared the general and a production pickup trucks. Trends for the drag as the vehicle geometry changes were same for CFD simulation and measurement. It proved capability of CFD for predicted steady flow over pickup truck [7].

The cargo area is the portion of the pickup truck located at behind the cabin driver to carry the goods in it. Some materials do not require covering over it like vegetables, furniture etc. While materials like cements, grains etc. require the covering over it. The present work aims to access effect of open cargo area when not in use. Also effect of covering cargo area on aerodynamic drag is assessed. It is observed that covering cargo area reduces drag. CFD analysis is done by using free software OpenFOAM.

\section{Methodology}

\subsection{OpenFOAM}

Open Field Operation and Manipulation (OpenFOAM) is Computational Fluid Dynamics software used here to analyze the airflow over pickup truck geometries for three cases. OpenFOAM has wide range of options to solve complex fluid flow with chemical reactions, turbulence, and heat [8].

Geometrical modelling of the pickup truck was done in open source software Salome and exported as STL (stereolithogrphy) file. SnappyHexMesh tool of OpenFoam was used to generate 
mesh using STL file of truck model as input. Initial flow field was created using openFOAM solver potentialFoam. Incompressible steady flow solver of openFOAM called simpleFoam was used. The velocity and pressure distribution over the geometries are visualized and discussed at varying speed from $40 \mathrm{~km} / \mathrm{hr}$ to $140 \mathrm{~km} / \mathrm{Hr}$. Flow visualization was done by plotting contour of pressure and velocity using post processor, paraFoam. For the flow analysis the pickup truck wheels are treated as not rotating.

\subsection{Basics of Aerodynamics}

When vehicle moves through air, it experience two forces, first along direction of motion resisting its motion called drag force $\left(F_{d}\right)$ and second perpendicular to motion lift force $\left(F_{1}\right)$. Drag and lift are important forces to be evaluated while designing the exterior shape of the vehicle. Drag force is important as fuel consumption depends on it, while lift force is related safety of vehicle. For comparison of performance of different body shapes of vehicle, drag force is expressed in dimensionless form called as drag coefficient. The drag force $\left(F_{d}\right)$ is calculated as follows [9]:

$$
F_{l}=\frac{1}{2} \rho V^{2} C_{d} A
$$

Where,

$\mathrm{F}_{\mathrm{d}}=$ Drag Force on vehicle, $\mathrm{N}$

$C_{d}=$ Drag Coefficient of vehicle

$A=$ Projected Area of the vehicle in direction of motion, $\mathrm{m}^{2}$

$\mathrm{V}=$ Velocity of vehicle, $\mathrm{m} / \mathrm{s}$

$\rho=$ Air Density, $\mathrm{kg} / \mathrm{m}^{3}$

Lift force is important as it will affect traction. The lift force $\left(F_{l}\right)$ is calculated as follows [9]:

$F_{l}=\frac{1}{2} \rho V^{2} C_{l} A$

Where,

$\mathrm{F}_{\mathrm{I}}=$ Lift Force on vehicle, $\mathrm{N}$

$C_{1}=$ Lift Coefficient of vehicle

$A=$ Projected Area of the vehicle in direction of motion, $\mathrm{m}^{2}$

$\mathrm{V}=$ Velocity of vehicle, $\mathrm{m} / \mathrm{s}$

$\rho=$ Air Density, $\mathrm{kg} / \mathrm{m}^{3}$

\subsection{Case Study Details}

Here purpose being to study aerodynamics with empty cargo space. Also, to compare performance of empty cargo with covered cargo space. Cargo space is covered in two ways. In first case cover is horizontal and second case cover is inclined with one end attach to rear of cabin. Here simplified model of commonly used pickup truck in Saudi Arabia is used. Cases considered here are as follows.

Case 1. Pickup truck cargo area is open (Figure 1).

Case 2. Pickup truck cargo area is horizontally covered (Figure 2). 
Case 3. Pickup truck cargo area is covered inclined and one end attached at top of cabin (Figure 3).

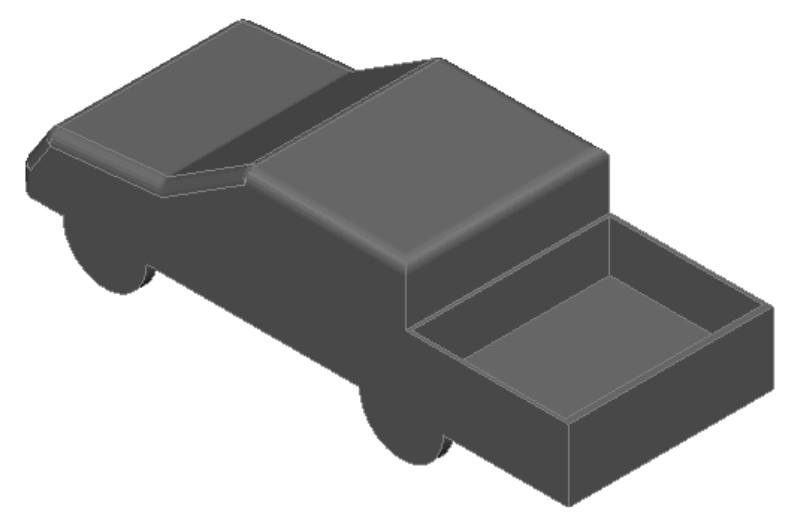

Fig. 1. Case 1 pickup truck cargo area open

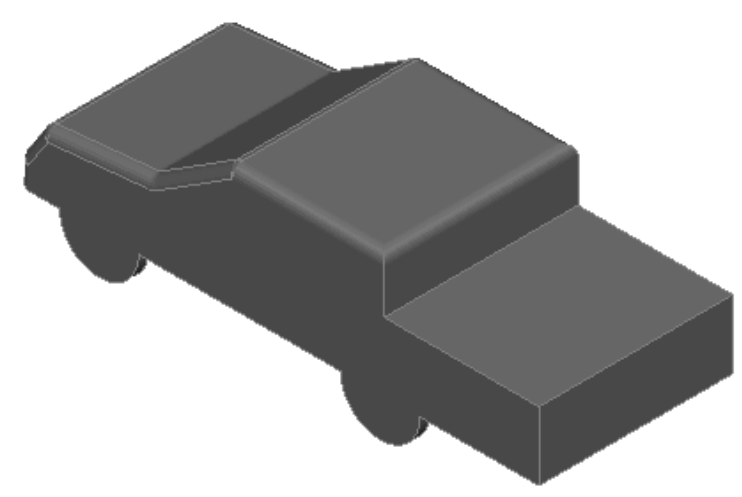

Fig. 2. Case 2 pickup truck cargo area covered

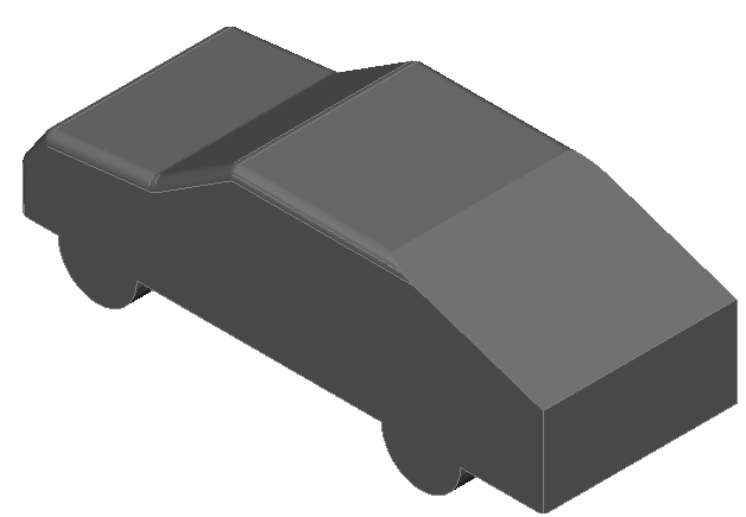

Fig. 3. Case 3 pickup truck cargo area with inclined cover

Typical dimensions considered here are of a pickup truck available in Saudi Arabia:

Overall Length of Model $=5.07 \mathrm{~m}$

Width of Model $=1.86 \mathrm{~m}$

Height of Model $=1.77 \mathrm{~m}$

\subsection{Computational Set Up}

Geometrical model of pickup truck along with cover were prepared in SALOME software. The model is then exported in STL (stereolithography) form to unstructured mesh generator of openFOAM, snappyHexMesh. Mesh is generated in space between STL of pickup truck and outer 
blockMesh [9]. Domain is shown in Figure 4 and Figure 5. Domain size was selected in such way to mimic road width.

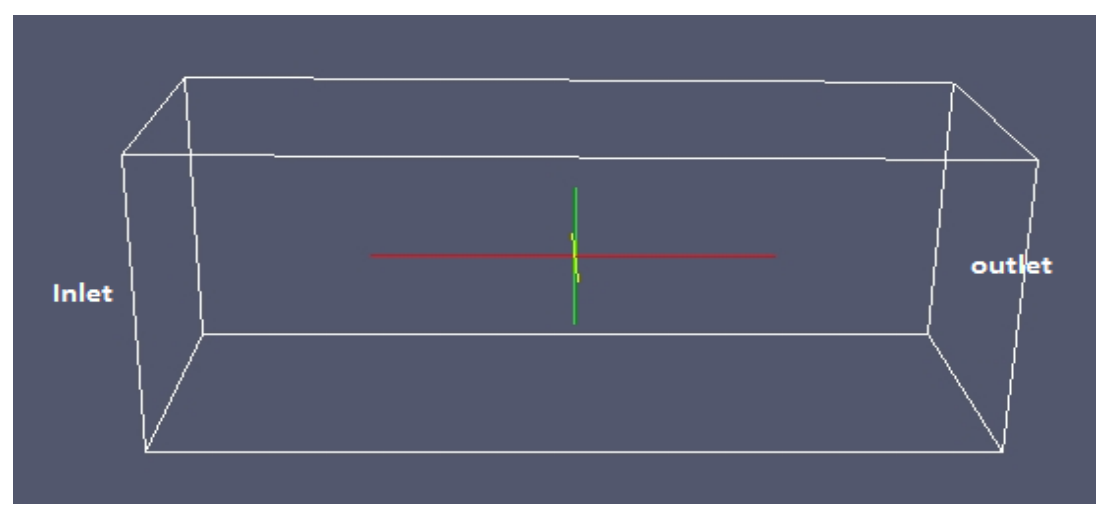

Fig. 4. Domain

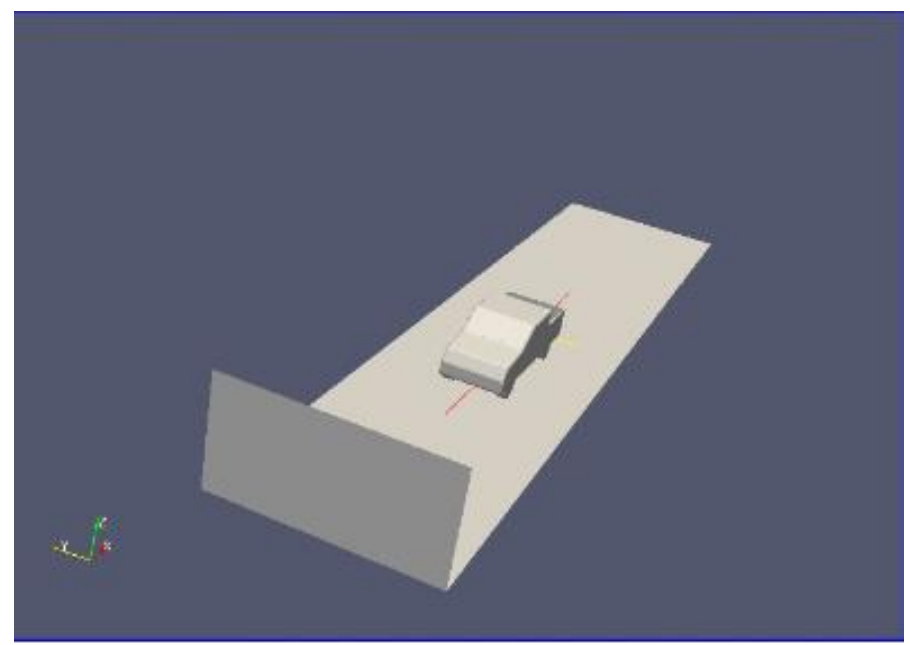

Fig. 5. Domain with geometry (view of post processor of OpenFOAM)

\subsection{Mesh Generation}

Unstructured Mesh is generated using utility of OpenFOAM called snappyHexMesh. Utility snappyHexMeshis used to create mesh for complicated geometry with boundary layer elements near wall. Mesh parameters are controlled by variables in the file snappyHexMeshDict [10]. Table 1 shows number of elements in computational domain for different cases. Mesh size was decided after conducting mesh sensitivity study.

\section{Table 1}

Mesh details for different cases

\begin{tabular}{ll}
\hline Case & Elements \\
\hline Case 1 & 450297 \\
Case 2 & 376499 \\
Case 3 & 358339 \\
\hline
\end{tabular}




\subsection{Boundary Conditions}

The speed of vehicle, thus speed of air with respect vehicle is same. Here speeds considered are $40 \mathrm{~km} / \mathrm{hr}, 60 \mathrm{~km} / \mathrm{hr}, 80 \mathrm{~km} / \mathrm{hr}, 100 \mathrm{~km} / \mathrm{hr}, 120 \mathrm{~km} / \mathrm{hr}$ and $140 \mathrm{~km} / \mathrm{hr}$. For each speed turbulence properties are calculated at inlet. For incompressible flow absolute value of pressure is not important, hence here outlet boundary condition for pressure set to $0 \mathrm{~Pa}$. The density and viscosity of the air are set as $1.125 \mathrm{~kg} / \mathrm{m}^{3}$ and $1.7894 \times 10^{-5} \mathrm{~kg} / \mathrm{ms}$ respectively.

\subsection{Turbulence Modelling}

As flow occurring is in turbulence range, turbulence is considered in simulation. As flow is highly disturbed, $k-\varepsilon$ is not sufficient to capture the flow. Suitable turbulence model for such flow is $k-\omega-S S T$ turbulence model as $\omega$ has proven reliability in separation zones [11].

\subsubsection{Turbulence intensity}

Turbulence is characterised by fluctuationg parameters. The turbulence intensity is defined as follow,

$$
I=\frac{u^{\prime}}{u^{\prime}}
$$

$I=$ turbulence intensity,

$u^{`}=\mathrm{RMS}$ (root-mean-square) of the velocity fluctuations

$\mathrm{u} \cdot=$ mean of free stream velocity

For flows inside duct and pipe, value of turbulence intensity at entry is high ranging from 1-10\%. Turbulent intensity inside fully developed flow is callculated as,

$$
I=0.16 \mathrm{Re}^{-1 / 8}
$$

For flows over bodies, the value of turbulent intensity is low of order of $0.05 \%$. Here turbulence intensity consided is $0.02 \%$.

\subsubsection{Turbulence length scale}

The turbulence length scale, $I$, measures eddy scale sizes in flow with turbulence. It defines the size of the large eddies in turbulent flows [11]. The characteristic size of the body $L$, and the size of the eddy $I$, can be related as,

$$
l=0.07 L
$$

\subsubsection{Calculation of $k$ and $\omega$}

It is required to specify turbulence properties at inlet. Required Turbulent properties Kinetic Energy $(k)$ and Specific Dissipation Rate $(\omega)$ are calculated as follows and Table 2 gives values of $k$ and $\omega$ at inlet for different speeds. 


$$
\begin{aligned}
& k=\frac{3}{2}(U I)^{2} \\
& \omega=\frac{k^{1 / 2}}{C \mu^{1 / 4} l}
\end{aligned}
$$

Table 2

Boundary condition for turbulence parameters

\begin{tabular}{llll}
\hline Speed, $\mathrm{Km} / \mathrm{hr}$ & Velocity, $\mathrm{m} / \mathrm{s}$ & $\mathrm{k}$ & $\omega$ \\
\hline 40 & 11.1 & 0.074 & 0.420 \\
60 & 16.7 & 0.167 & 0.630 \\
80 & 22.2 & 0.296 & 0.840 \\
100 & 27.8 & 0.463 & 1.051 \\
120 & 33.3 & 0.667 & 1.261 \\
140 & 38.9 & 0.907 & 1.471 \\
\hline
\end{tabular}

\section{Results}

Case 1; Figure 6 shows the pressure field on the surface of body of the pickup truck with case 1 with open cargo area. On top of cabin pressure shown is lesser indicating creation of lift force. Because of recirculation, pressure inside cargo area is reduced. This indicates that the case is expected to have more drag force. Figure 7 shows vector plot for case 1 . Recirculation in cargo area and at rear of cargo area seems too stronger as compared to case 2 and case 3 thus gives reason of having more drag coefficient. Figure 8 shows velocity contour for case 1 . It shows low velocity in cargo area and back side cargo area. Table 3 shows value of drag coefficient $C_{d}$ and lift coefficient $C_{l}$ for case 1 for different speed of pickup truck.

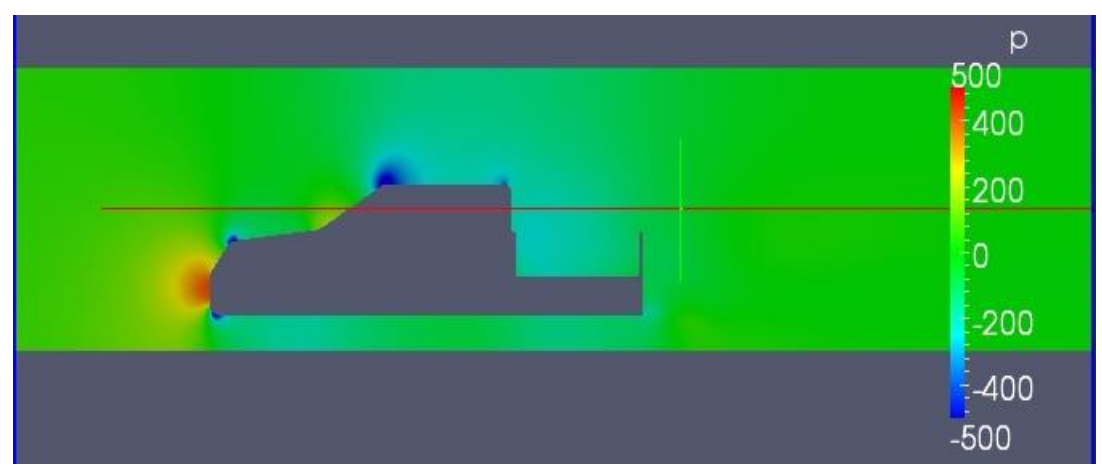

Fig. 6. Pressure Contour for case 1

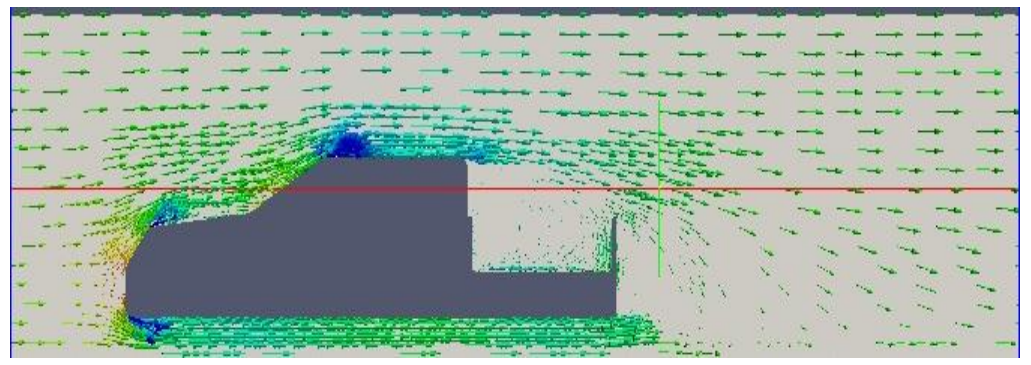

Fig. 7. Velocity Vector plot for case 1 


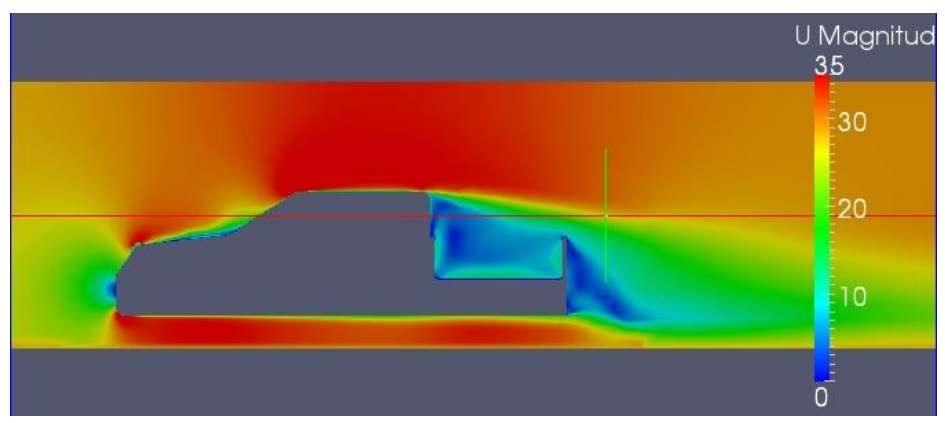

Fig. 8. Velocity Contour for case 1

Table 3

Values of $C_{d}$ and $C_{1}$ for case 1

\begin{tabular}{lll}
\hline Speed $\mathrm{km} / \mathrm{hr}$ & $\mathrm{C}_{d}$ & $\mathrm{C}_{\mathrm{I}}$ \\
\hline 40 & 0.634 & 0.412 \\
60 & 0.635 & 0.438 \\
80 & 0.64 & 0.439 \\
100 & 0.637 & 0.433 \\
120 & 0.632 & 0.423 \\
140 & 0.633 & 0.427 \\
\hline
\end{tabular}

Case 2; Figure 9 shows the pressure filed on the surface of body of the pickup truck for case 2 with cargo area covered horizontally. On top of cabin pressure shown is lesser indicating creation of lift force. Here as recirculation area is reduced it is expected have less drag than case 1 . This indicates that the case 2 is expected to have less drag force as compared to case 1 . Figure 10 shows vector plot for case 2. Recirculation above cargo area and at rear of cargo area seems to weaker than case 1 , thus gives reason of having low drag coefficient. Figure 11 shows velocity contour for case 2 . It shows relatively high velocity above cargo area and back side of cargo area. Table 4 shows value of coefficient of drag $C_{d}$ and coefficient of lift $C_{\mid}$for case 2 for different speed of pickup truck. Table 4 also shows percentage reduction in drag coefficient as compared to case 1 . It shows about average $5.3 \%$ reduction in drag coefficient as compared to case 1 .

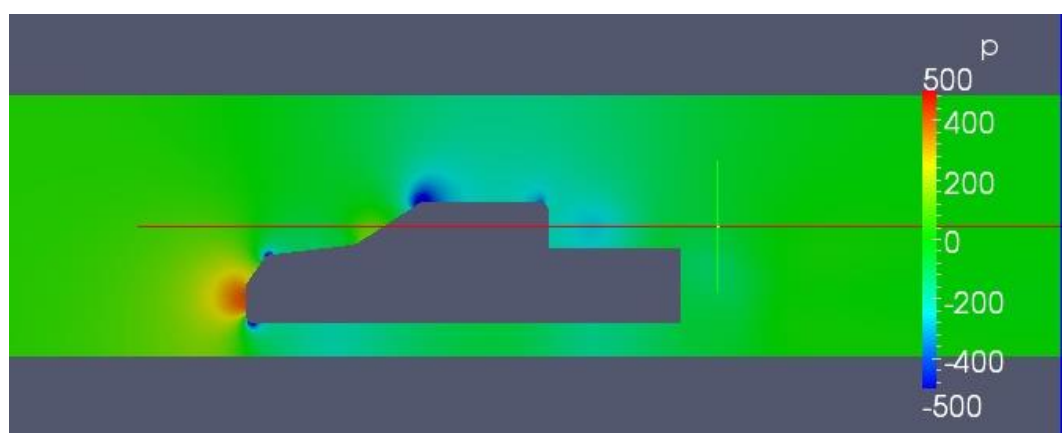

Fig. 9. Pressure Contour for case 2

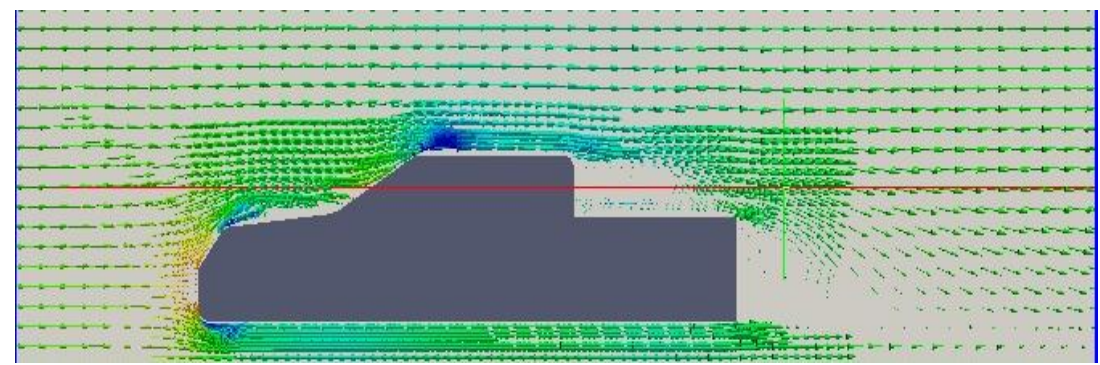

Fig. 10. Velocity Vector plot case 2 


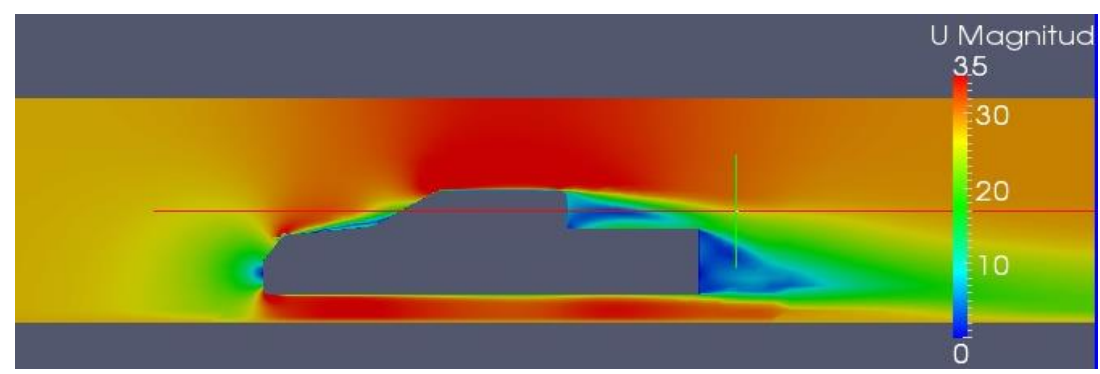

Fig. 11. Velocity Contour Case 2

Table 4

Values of $\mathrm{C}_{d}$ and $\mathrm{C}_{1}$ forcase 2

\begin{tabular}{llll}
\hline Speed km/hr & $C_{d}$ & $C_{l}$ & \% Change in $\mathrm{Cl}_{1}$ \\
\hline 40 & 0.608 & 0.368 & -10.7 \\
60 & 0.603 & 0.376 & -14.1 \\
80 & 0.599 & 0.374 & -14.8 \\
100 & 0.6 & 0.382 & -11.8 \\
120 & 0.599 & 0.378 & -10.6 \\
140 & 0.6 & 0.386 & -9.6 \\
\hline
\end{tabular}

Case 3; Figure 12 shows the pressure field on the surface of body of the pickup truck with case 3 with cargo area covered inclined way and attached to rear of cabin top. On top of cabin pressure shown is lesser indicating creation of lift force. But pressure on top of pickup truck is bigger than case 2. Here as recirculation area is reduced it is expected have less drag than case 2 . This indicates that the case 3 is expected to have lesser drag force as compared to case 2. Figure 13 shows vector plot for case 3. Recirculation above cargo area and at rear of cargo area seems to weaker than case 2, thus gives reason of having low drag coefficient. Figure 14 shows velocity contour is for case 3 . It shows relatively high velocity above cargo area and back side cargo area. Table 5 shows value of coefficient of drag $C_{d}$ and coefficient of lift $C_{I}$ for case 3 for different speed of pickup truck. Table 5 also shows percentage reduction in drag coefficient as compared to case 1 . It shows about average $13.5 \%$ reduction in drag coefficient as compared to case 1 .

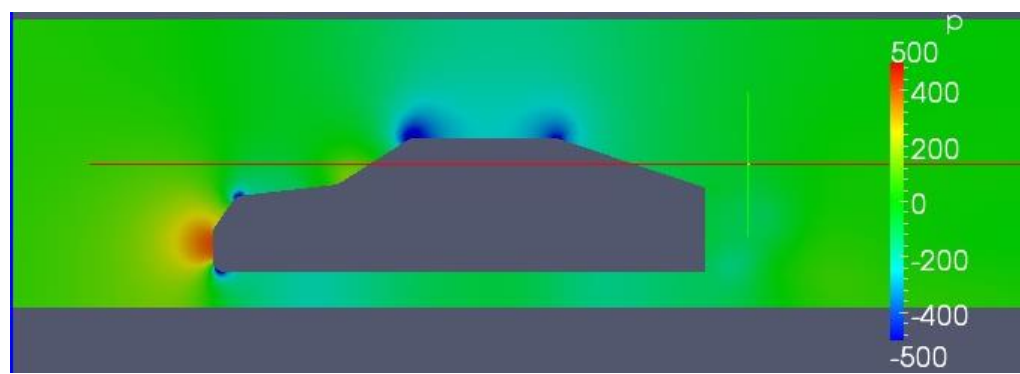

Fig. 12. Pressure Contour for Case 3

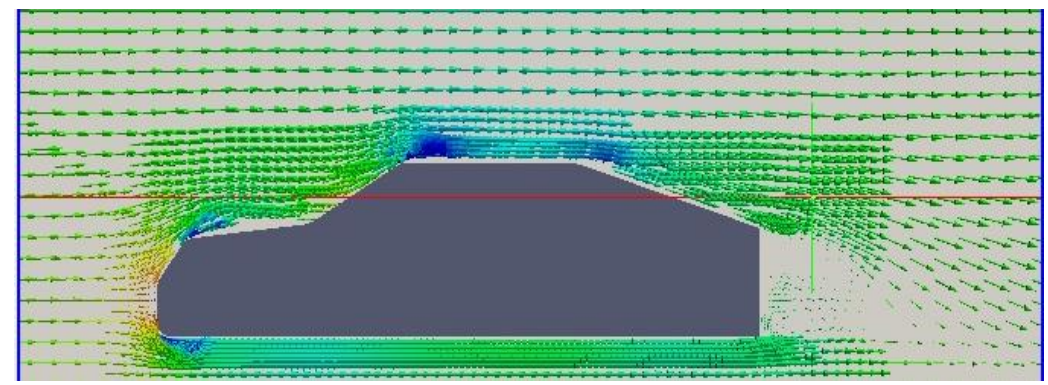

Fig. 13. Velocity Vector plot for Case 3 


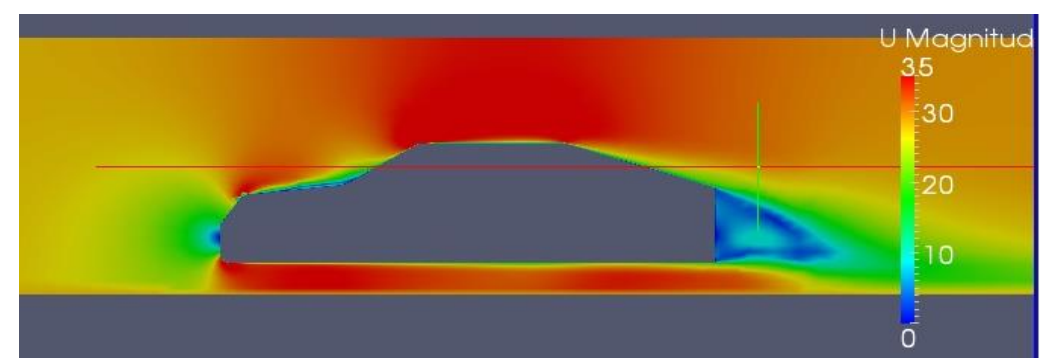

Fig. 14. Velocity Contour for Case 3

Table 5

Values of $C_{d}$ and $C_{1}$ for case 3

\begin{tabular}{lllll}
\hline Speed, $\mathrm{km} / \mathrm{hr}$ & $\mathrm{C}_{\mathrm{d}}$ & $\mathrm{C}_{\mathrm{I}}$ & \% Change in $\mathrm{C}_{\mathrm{d}}$ & \% Change in $\mathrm{C}_{\mathrm{I}}$ \\
\hline 40 & 0.555 & 0.582 & -12.5 & 41.2 \\
60 & 0.551 & 0.587 & -13.2 & 34.0 \\
80 & 0.549 & 0.589 & -14.2 & 34.1 \\
100 & 0.548 & 0.594 & -14.0 & 37.2 \\
120 & 0.547 & 0.593 & -13.4 & 40.2 \\
140 & 0.548 & 0.594 & -13.4 & 39.1 \\
\hline
\end{tabular}

Figure 15 shows comparison of velocity contour for three cases. Third case shows reduction in wake region. Variation of drag coefficient for three different cases are shown in Figure 16 for different speeds. For each case it is observed that variation of drag coefficient with speed is negligible. Case 1 shows highest average drag coefficient of 0.64 . Case 2 shows moderate average drag coefficient of 0.6, whereas Case 3 shows lowest average drag coefficient of 0.55. As discussed earlier in case 2 recirculation volume is reduced as compared to case 1 , hence drag is reduced. Further for case 3 as recirculation volume is reduced as compared to case 2 , further reduction in drag force is observed.

Variation of lift coefficient for three different cases are shown in Figure 17 for different speeds. For each case it is observed that variation of lift coefficient with speed is negligible. Case 3shows highest average lift coefficient of 0.59 . Case 1 shows moderate average lift coefficient of 0.43 , whereas Case 2 shows lowest average lift coefficient of 0.38 . In case of open cargo, low pressure region on top of cabin increases immediately giving moderate lift force. Case 3 shows significant rise in lift coefficient by $37.7 \%$ as compared to case 1 necessitating designer to check whether it will give required traction and tire contact with road from safety point of view.
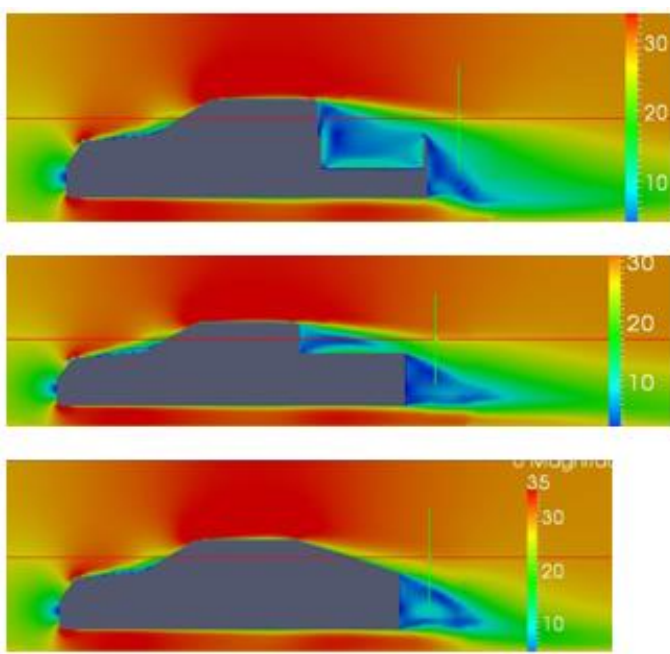

Fig. 15. Comparison of velocity contour for three cases 


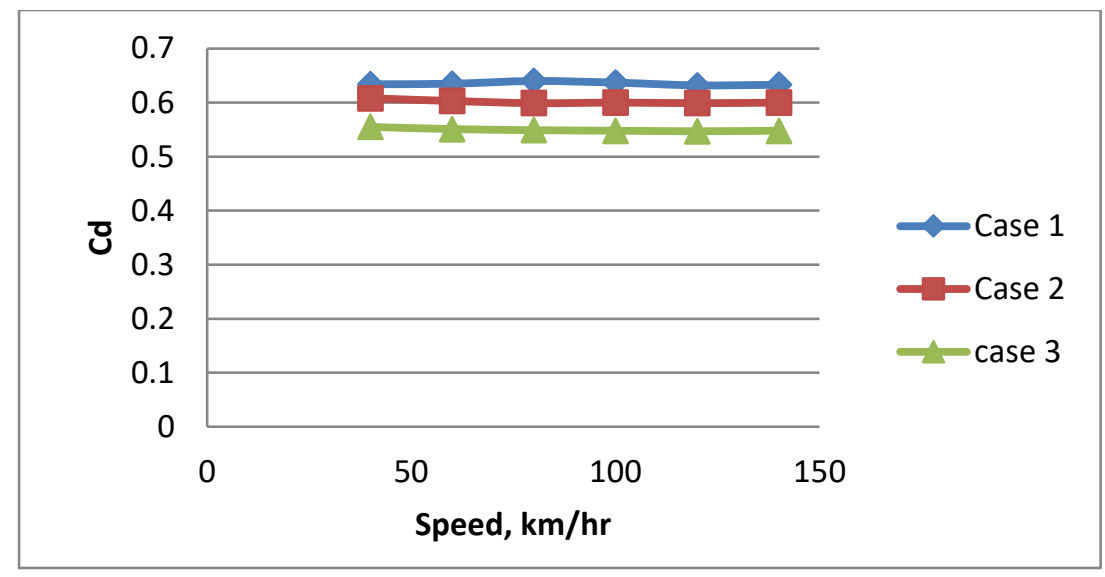

Fig. 16. Variation of Cdwith Speed for 3 cases

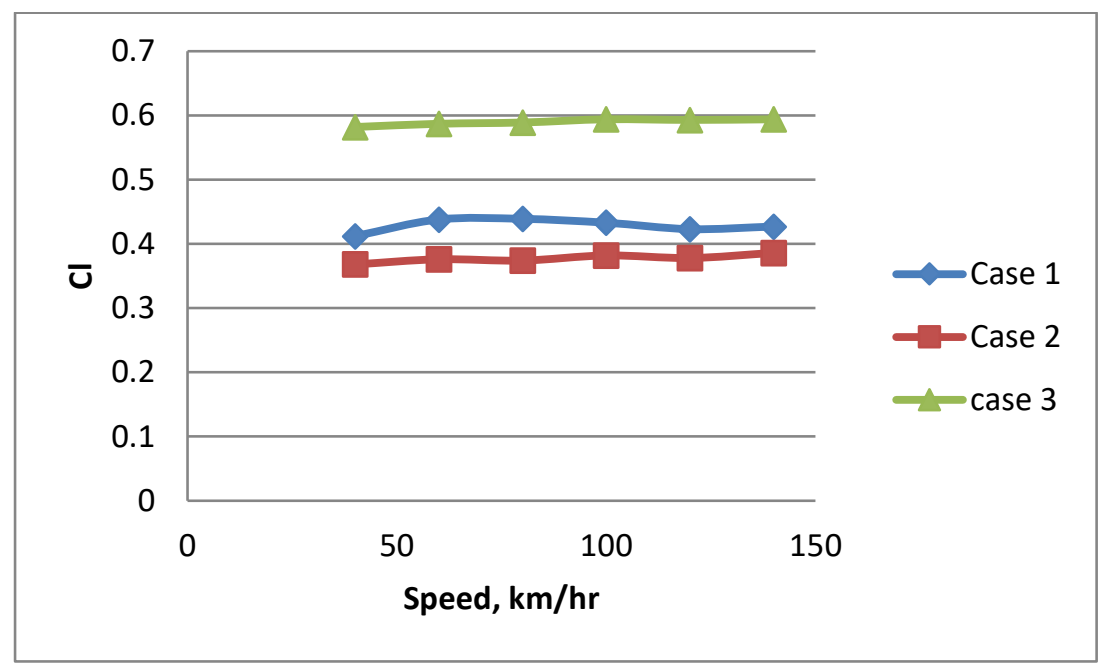

Fig. 17. Variation of $C_{1}$ with Speed for 3 cases

\section{Conclusions}

Covered cargo area of pickup truck leads to reduction in coefficient of drag as recirculation zone area is reduced in comparison to open cargo area. Inclined cover of pickup truck gives further reduction in coefficient of drag in comparison to horizontal cover as recirculation one is further reduced. Case 3 shows significant rise in lift coefficient by $37.7 \%$ as compared to case 1 necessitating designer to check whether it will give required traction and tire contact with road from safety point of view.

\section{Acknowledgement}

This research was funded by Imperial College of Engineering and Research, Pune University, Pune, India.

\section{References}

[1] Bahram Khalighi, General Motors R\&D Center, VAD Lab, "Pickup Truck Aerodynamics A PIV Study" Internal report.

[2] Dasar, Mahesh H., Deepak J. Patil, and Raviraj M. "CFD Simulation of Pickup Van." International Journal of Engineering Research \& Technology (IJERT) 2, no. 12 (2013): 1995-2004.

[3] Ha, Jongsoo, Shigeru Obayashi, and Yasuaki Kohama. "Drag characteristics of a pickup truck according to the bed geometry." In 7th IASME/WSEAS International Conference on Fluid Mechanics and Aerodynamics, FMA'09, pp. 122127. 2009. 
[4] Kim, Julie, Justin Pattermann, Varun Menon, and Wael Mokhtar. "A CFD Study of Pickup Truck Aerodynamics." Proceedings of the 2011 ASEE North Central \& Illinois-Indiana Section Conference (2011).

[5] Adem, Feysal Ahmed. "Drag reduction of pickup truck using add-on devices." Master's thesis, California State University-Sacramento, 2010.

[6] Mukda, Prachya. "Effect from Accessories on Pickup Aerodynamics by Computational Fluid Dynamics." In 6th Int'l Conference on Advances in Engineering Sciences and Applied Mathematics (ICAESAM'2016), pp. 59-63. 2016. https://doi.org/10.15242/IIE.E1216022

[7] Yang, Zhigang, and Bahram Khalighi. CFD simulations for flow over pickup trucks. No. 2005-01-0547. SAE Technical Paper, 2005. https://doi.org/10.4271/2005-01-0547

[8] Melb $\varnothing$, Henrik Kaald. "A Graphical User Interface for the Computational Fluid Dynamics Software OpenFOAM." Master's thesis, Norwegian University of Science and Technology, 2014.

[9] Jathar, L. D., and S. L. Borse. "Study of Flow over Car by Changing Different Parameters using Open Foam." International Journal of Fluids Engineering 6, no. 1 (2014): 29-38.

[10] Rahimi, Hamid, Elia Daniele, Bernhard Stoevesandt, and Joachim Peinke. "Development and application of a grid generation tool for aerodynamic simulations of wind turbines." Wind Engineering 40, no. 2 (2016): $148-172$. https://doi.org/10.1177/0309524X16636318

[11] Davidson, Lars. "Fluid mechanics, turbulent flow and turbulence modeling." Chalmers University of Technology, Goteborg, Sweden (Nov 2011) (2018).

[12] Abinesh, J., and J. Arunkumar. "CFD analysis of aerodynamic drag reduction and improve fuel economy." International Journal of Mechanical Engineering and Robotics Research 3, no. 4 (2014): 430-440.

[13] Hassan, S. M. Rakibul, Toukir Islam, Mohammad Ali, and Md. Quamrul Islam. "Numerical study on aerodynamic drag reduction of racing cars." Procedia Engineering $90 \quad$ (2014): $308-313$. https://doi.org/10.1016/i.proeng.2014.11.854

[14] Das, Rubel Chandra, and Mahmud Riyad. "CFD analysis of passenger vehicleat various angle of rear end spoiler." Procedia Engineering 194 (2017): 160-165. https://doi.org/10.1016/i.proeng.2017.08.130 